\title{
Risk and self-respect
}

Article

Accepted Version

Baderin, A. and Barnes, L. (2020) Risk and self-respect. British Journal of Political Science, 50 (4). pp. 1419-1437. ISSN 1469-2112 doi:

https://doi.org/10.1017/S0007123418000212 Available at https://centaur.reading.ac.uk/79482/

It is advisable to refer to the publisher's version if you intend to cite from the work. See Guidance on citing.

To link to this article DOI: http://dx.doi.org/10.1017/S0007123418000212

Publisher: Cambridge University Press

All outputs in CentAUR are protected by Intellectual Property Rights law, including copyright law. Copyright and IPR is retained by the creators or other copyright holders. Terms and conditions for use of this material are defined in the End User Agreement.

\section{www.reading.ac.uk/centaur}

\section{CentAUR}

Central Archive at the University of Reading

Reading's research outputs online 


\title{
Risk and self-respect ${ }^{1}$
}

Alice Baderin, Nuffield College, University of Oxford alice.baderin@nuffield.ox.ac.uk

Lucy Barnes, School of Public Policy, University College London I.barnes@ucl.ac.uk

\begin{abstract}
What is the nature of the experience of risk? Risk can impose distinctive burdens on individuals: making us anxious, impairing our relationships, and limiting our ability to plan our lives. On the other hand, risky situations are sometimes exciting, liberating, and even empowering. The article explores the idea that risk can result in benefits for the individuals who bear it. Specifically, we evaluate John Tomasi's claim that the experience of economic risk is a precondition of individual self-respect. Philosophical claims about the social bases of self-respect such as Tomasi's have not been subjected to sufficient empirical scrutiny. The article exemplifies an alternative approach, by integrating philosophical argument with the analysis of large-scale survey data. Whilst Tomasi's claim has force in some contexts, evidence from the economic domain shows that risk tends to undermine rather than to support self-respect.
\end{abstract}

Key words: risk, self-respect, empirical political philosophy

What is the nature of the experience of risk? In other words, what is it like to live with the possibility, but not certainty, that some adverse future event will occur? On one

1 Forthcoming at the British Journal of Political Science.

https://www.cambridge.org/core/journals/british-journal-of-political-science

Earlier versions of the paper were presented at the CELPA Workshop, University of Warwick; Political Theory Workshop, University of York; CSSJ Workshop, University of Oxford; Nuffield Postdoctoral Research Seminar in Politics and Sociology, University of Oxford; and a workshop on 'Doing Realist Political Theory' at the University of Sheffield. We thank participants on those occasions for their helpful feedback. For valuable written comments we are especially grateful to Michael Bennett, Heejung Chung, Matthew Clayton, David Miller, Adam Swift and Jo Wolff. The data, replication instructions, and the data's codebook can be found at doi:10.7910/DVN/AUX9W1, and the online appendix can be found at https://www.dropbox.com/s/tpsavrmoezqkwr4/Risk\%20and\%20selfrespect\%20Appendix.pdf?dl=0 until its publication through the Journal's website. 
account, risk is harmful even when the potential negative outcomes do not materialize: it provokes anxiety, limits individual choice, and constrains our ability to plan our lives. Consider two individuals who enjoy an equal standard of housing, except that one has a secure tenancy and the other could be evicted at short-notice. ${ }^{2}$ Now imagine that the insecure tenant is, in fact, never required to leave. From one perspective, the lives of these individuals have, in the end, gone the same. Nevertheless, we can see that there are some important respects in which the insecure tenant is disadvantaged. For example, she may suffer psychological distress at the prospect of losing her home. She may also, with good reason, not invest in building relationships within her local community. We can imagine similar cases involving insecurity in people's status or access to resources across a range of domains, such as employment, immigration or healthcare. Even when the possible adverse events do not occur, the experience of insecurity itself has the capacity to damage people's lives, sometimes in profound ways. ${ }^{3}$

There is, however, a contrasting story we can tell about the experience of risk. Risk is sometimes exciting. But more than this, risky situations can be liberating and empowering; they offer us opportunities to exercise agency, to test ourselves and to develop self-control. Thus the possibility of a wholly secure life will seem dull and oppressive to many. Moreover, we voluntarily undertake risky activities, sometimes in part because they are risky. ${ }^{4}$ Whether the experience of risk is one of excitement or

2 Wolff 2009, 217.

3 On harms stemming from unrealized risks, see Perry 2007, 198-9; Wolff and de-Shalit 2007, 65-73.

4 On the goods of risk, see Giddens 1991, 132-33; Lupton and Tulloch 2002, 113-24. 
anxiety, of power or powerlessness, the implication is that we cannot judge how well-off people are simply by assessing the goods that they currently possess; rather 'one's present well-being must make reference to future states by means of the notions of risk and insecurity or vulnerability. ${ }^{5}$ However, we have two very different perspectives on the direction in which this observation takes our thinking about justice. On the first account risk compounds disadvantage, whereas the second vision suggests that risk can lead to benefits for the individuals who bear it.

These two broad visions of risk provide the starting point for this paper. Each of these accounts surely captures something true about the role of risk in human experience. The challenge is to specify more precisely the different types of benefits and burdens of risk, for various forms of risk, in distinct contexts. The paper contributes to this task by exploring a version of the second 'risk as a good' account that is advanced by John Tomasi in Free Market Fairness. Specifically, we evaluate Tomasi's claim that the 'experience of risk seems to be an essential precondition of the sort of self-respect that liberals value'. ${ }^{6}$ In Rawlsian terms, Tomasi suggests that economic arrangements that expose individuals to risk are among the social bases of self-respect: 'those aspects of basic institutions normally essential if citizens are to have a lively sense of their worth as persons and to be able to advance their ends with self-confidence'. ${ }^{7}$ Thus he alleges that left liberals, in advocating welfare and labour market policies that provide greater

5 Wolff 2009, 217.

6 Tomasi 2012, 80.

7 Rawls 2001, 59. 
economic security, would undermine the conditions for the realization of one of their own most fundamental values.

Our motivation for focussing on Tomasi is twofold. First, he advances an interesting substantive claim about the benefits of economic risk, which opens up important wider questions about how individuals experience diverse forms of risk. Secondly, Tomasi offers an appealing vision of how to do political philosophy; an account on which we build our theory starting from the observation of everyday human experience. He warns us that the passion for idealization 'can make philosophers impervious to moral learning. Their methodological impulse is to climb up and away from the experiences of ordinary citizens, rather than to come down and listen closely to them ${ }^{\prime}{ }^{8}$ However, Tomasi fails to make good on this bottom-up methodological vision, since he does not engage with empirical evidence about the impact of economic risk on individual self-concept. The paper takes up Tomasi's suggested method by presenting new analyses of Health Survey for England (HSE) and British Household Panel Survey (BHPS) data. Thus we exemplify a more empirically-based approach to philosophical debate about the social bases of selfrespect.

Our results show that economic risk tends to undermine rather than to support selfrespect. However, the paper also identifies qualitative evidence linking the experience of risk, in a variety of forms, with the development of positive self-attitudes and emotions. We explain these divergent findings by identifying a number of crucial dimensions along

8 Tomasi 2012, 214. See also 60-68. 
which risky situations differ, to which Tomasi's account is not sensitive. Thus, whilst Tomasi appeals to a vision of risk that has force in some contexts, the evidence does not support his case against welfare and labour market policies that offer greater security in the economic sphere.

A few preliminary remarks are needed here about the complex and contested notion of risk. Here we conceptualize a risky situation as a context in which an individual faces, and is aware that she faces, the possibility of an adverse future event. We are interested in how people experience downside risks in the pre-outcome phase; in other words, we investigate the effects of risk itself, independently of how those risks play out. Of course, many risks also involve potential gains, and there is an obvious sense in which risks are good for people when such benefits are realized. Moreover, it seems likely that the period of insecurity itself will be experienced differently when there is a potential upside. However, our focus on downside risks is consistent with Tomasi's account of the janitor case (see section I) and with his critique of welfare provision more generally. Tomasi's intriguing suggestion is that there is an important good to be realized through experiencing the possibility of something bad happening to us. Secondly, we note that a distinction is commonly drawn between risk and uncertainty: where a risky situation is one in which we do not know what will happen, but we can attach probabilities to the various possible outcomes; in a situation of uncertainty we are unable even to identify the relevant probabilities. The types of economic threats we consider represent neither instances of pure risk, in which we have secure knowledge of the relevant probabilities, 
nor cases of pure uncertainty, in which we lack any credible information with which to estimate probabilities. We prefer the term risk to describe these intermediate cases.

A third central problem in the definition of risk concerns the distinction between actual and perceived risk. As the reference to awareness in the above definition implies, if we are interested in the impact of risk on self-concept, we are inevitably involved in the domain of perceptions. ${ }^{9}$ This invites the objection that we are catering to subjective responses to risk, which, we know from a large body of research, exhibit various problematic irrationalities. ${ }^{10}$ We have two responses to this concern. First, the objection is less pressing in the economic domain with which we are concerned, where there is a consensus in the empirical literature that subjective worries are responsive to the actual rates of occurrence of adverse events. Across individuals, the experience of objective economic shocks leads to greater feelings of insecurity in terms of job loss, wealth, and health. ${ }^{11}$ Across countries and over time, subjective employment insecurity closely tracks the unemployment rate. ${ }^{12}$ Secondly, we are focussed here on how risk shapes selfrespect, not yet on the further question of what we ought to do in response to any such connections. Thus we do not deny the need for some criteria of epistemic reasonableness when thinking about action to secure the social bases of self-respect.

9 Thus we are not dealing with cases of 'pure risk', in the sense of risk that is both unrecognized and unrealized. On the moral status of pure risk, see Finkelstein 2003; Oberdiek 2017; Perry 2007, $200-2$.

See, for example, Sunstein 2005.

11 Hacker, Rehm and Schlesinger 2013; Jacobs and Newman 2008, 82-9.

12 Green 2009. 
The remainder of the paper proceeds in four main parts. Section I unpacks Tomasi's argument linking risk with the attainment of self-respect. Specifically, we identify three mechanisms through which the experience of risk might further individual self-respect. II discusses some existing evidence that bears on the question of the relationship between risk and self-respect, as well as presenting our new analyses of HSE and BHPS data. Whilst some qualitative research reveals the benefits of risk for self-worth and confidence, our analyses show a consistently negative relationship between economic risk and self-respect. III explains our pattern of findings by outlining some key dimensions along which risky situations differ, which in turn shape how risk is experienced. IV briefly addresses a potential objection to our empirically-based approach to philosophical debate about the social bases of self-respect.

\section{TOMASI ON RISK AS A PRECONDITION OF SELF-RESPECT}

Tomasi's claim that risk underpins self-respect is advanced in the context of a wider project, one of whose central aims is to show that a wide range of economic freedoms should be accorded the status of basic liberties. On Rawls's view, only freedom of occupational choice and the right to own private property belong in this category, on a par with civil and political liberties. Further questions about the organization of the economy, such as the ownership of productive property, are to be determined at the legislative stage and shaped by a society's particular circumstances and history. ${ }^{13}$ Tomasi argues that this restrictive Rawlsian account is guilty of unjustified 'economic

13 Rawls 1982, 53. 
exceptionalism' and we should admit a much wider range of basic economic liberties, including the right to work the number of hours I choose, to negotiate the pay for which I work, to own productive property and to decide how much to save for healthcare or for my children's education. Although not absolute, this broader set of economic freedoms should receive constitutional protection and ought to be limited only for the sake of securing other basic liberties. This argument for 'thick economic liberty' is intended to challenge a wide range of policies that Tomasi associates with 'European social democracy': various forms of labour market regulation, as well as social security provision and extensive redistributive taxation. ${ }^{14}$

Tomasi most often grounds the case for an extensive set of economic basic liberties in the idea of 'responsible self-authorship': the value of individuals assessing, choosing and pursuing their own life goals. He also repeatedly emphasizes the need for one to be, and to think of oneself as, 'the central cause of the life one is leading'. ${ }^{15}$ A wide range of economic liberties are said to be crucial to our self-authorship and sense of self-ascause:

'A society that denies people the chance to take up questions of long-term financial planning for themselves, or that restricts the ways in which individuals and families can respond to such questions, thereby diminishes the capacity of citizens to become fully responsible and independent agents. So too a society

\footnotetext{
14 Tomasi 2012, 216. Tomasi argues that his theory does leave room for a minimal safety net. But it is difficult to see how this claim fits with his view that the economic liberties are basic.

15 Tomasi 2012, 83.
} 
that limits the freedom of individuals to negotiate the specific terms of their employment, or that makes their ownership of productive property subject to calculations about social expediency, no matter how benevolent their intentions in doing so, thereby creates social conditions in which the moral powers of citizens can be exercised and developed in only a stunted way'. ${ }^{16}$

Tomasi's argument rests on a false dichotomy between state coercion on economic matters on the one hand, and free exercise of individual agency on the other: there is little recognition of the reality of coercion by non-state actors. For example, he claims that in a society in which employment hours and pay are highly socially regulated, 'citizens would no longer be authors of their own lives. Decisions about matters that affect them intimately would have been taken out of their hands and decided for them by others'. ${ }^{17}$ But he does not adequately address the ways in which, in the absence of regulation, such decisions are taken out of the hands of many individual citizens in the face of the power of employers and limited choice within the labour market. Thus Tomasi's own arguments about the importance of individuals being able to exercise agency in the economic domain point towards a more expansive role for the state in the economy than he wishes to admit. ${ }^{18}$

Given the difficulties with Tomasi's self-authorship argument, we treat his claim about the value of risk as an interesting alternative way of framing the case for thick economic

16 Tomasi 2012, 80-81.

17 Tomasi 2012, 77.

18 On the freedom-constraining effects of free markets, see Cohen 2016; Gourevitch 2014; Gowder 2014. 
liberty. ${ }^{19}$ Whilst Tomasi himself slides between claims about self-authorship and risk, the two notions are not identical. For example, consider a free market society in which economic risk is low due to the structure of people's skills and preferences. Or think about a case in which individuals voluntarily purchase comprehensive insurance against economic risk. ${ }^{20}$ In these examples, individuals are missing the ongoing experience of economic insecurity, but others do not act to undermine their economic self-authorship in the way that Tomasi finds problematic. What would Tomasi say to these cases? Would he see a risk-free economic life as problematic, even if it arose without interference in the exercise of individual economic agency? Since Tomasi does not explicitly distinguish his claims about the value of the experience of risk from his arguments about economic self-authorship, we do not have a firm answer to this question. However, to some extent our exploration of the relationship between risk and self-respect is independent of the interpretive issue; we treat Tomasi's remarks about the value of risk as interesting and worth further examination in their own right.

But why and how might risk underpin self-respect and, conversely, how might the absence of risk undermine self-respect? Following Charles Murray, Tomasi introduces the example of an individual who works as a janitor and thereby supports his family: 'Such people, Murray suggests, are doing something genuinely important with their lives ... If those same people lived under a system in which they were heavily insulated from

19 Depending on how we fill out the risk argument (see below), the idea of individual agency may come back in. But it is helpful, in the first instance, to separate the claim about risk from that about selfauthorship.

20 We are grateful to Matthew Clayton for suggesting these cases. 
economic risk, for example, by being assured that they and their children will be well provided for whether or not they themselves contribute, then that status goes away'. ${ }^{21}$ In what ways is the status of the janitor undermined in the context of a welfare system that provides him and his family with economic security? More generally, why is it that 'By insulating people from economic risks, the European model denies ordinary citizens opportunities to feel the special sense that they have done something genuinely important with their lives' ${ }^{22}$

The claim that the experience of economic risk enhances self-respect initially looks puzzling. How can the threat that something bad will happen to us be good for our sense of self ${ }^{23}$ In order to make sense of Tomasi's claim, it is useful to distinguish three potential mechanisms linking risk with greater self-respect. First, risk might have a direct positive impact on individual self-concept. Perhaps facing an unknown future gives us a keener sense of our own agency. The experience of risk might also cause us to reflect further on our commitments. In this way, our goals will become more our own and we

21 Tomasi 2012, 80.

22 Tomasi 2012, 80. A more radical right-wing view holds that failure (as opposed to risk) is a good that is denied people by the welfare state. This, we take it, is not Tomasi's view. Thus, as we understand it, Tomasi's claim about the value of risk does not represent an all-things-considered defence of riskexposing economic arrangements. This would require that we also weigh the implications of how risks turn out, for self-respect and for other values.

There is a particular puzzle about how subjective economic risk (expecting things to go badly in economic terms) could be positively related to confidence (or expecting one's plans to be fulfilled). Within our analysis the tension is less acute than it might appear, since the measures apply to different domains: subjective risk relates to the economic sphere (specifically to job security), whereas our confidence measure is global. For example, perhaps as my sense that my job is insecure increases, this might lead me to work harder and thereby gain confidence about my abilities and prospects in life in general. We thank an anonymous reviewer for drawing our attention to this potential tension. 
may come to value them more highly in the face of the possibility that they will not be realized. Secondly, the beneficial effects of risk on self-respect might be mediated by behaviour. Understood in this way, Tomasi's claim is that individuals act differently when they are insecure and, specifically, they behave in ways that are conducive to the development or maintenance of self-respect. For example, perhaps people work harder under risk and thereby gain in confidence or reinforce their sense of their own worth. Thirdly, we should consider the social meaning of risk: when an individual or organization exposes us to, or declines to protect us against, avoidable risk they express something about how they regard us. Specifically, allowing an individual to bear a risk can be a way of communicating trust and confidence in her capacities that may, in turn, reinforce her self-confidence. Tomasi evokes this picture of the expressive dimension of risk when he asks: 'How can individuals have self-respect if their fellow citizens deny them the right to decide for themselves how many hours they will work each week and under what precise terms and conditions? How can they think of themselves as esteemed by their fellow citizens if those citizens call on the coercive force of the law to impede them in deciding for themselves how much (or little) to save for retirement, the minimum wage they may find acceptable for various forms of work, or to dictate the parameters of the medical care that will be available to them $?^{24}$

\section{EMPIRICAL EVIDENCE}

\section{A. ECONOMIC RISK HARMS SELF-RESPECT}

24 Tomasi 2012, 83-4. Emphasis added. 
We have briefly unpacked Tomasi's claim to show that there are at least three plausible pathways through which the experience of economic risk might enhance individual selfrespect. However, for each of the positive mechanisms outlined above, there is also a negative story we can tell about the impact of risk on self-respect. Perhaps the experience of risk creates feelings of helplessness, rather than enhancing our sense of agency. In the face of risk, we might become demotivated, rather than driven. And perhaps the true social meaning of economic risk is an expression of disregard and devaluing, rather than trust and confidence. In order to adjudicate between these competing narratives we need to bring empirical evidence to bear.

Empirical researchers are increasingly turning their attention to questions about the nature and consequences of economic insecurity. For example, there is growing interest among political scientists in how perceptions and experiences of economic insecurity shape policy attitudes. ${ }^{25} \mathrm{~A}$ more established body of research addresses the individual level impact of job insecurity. We have long known that job loss and unemployment tend to be bad for people in various ways, but since the mid-1980s researchers have also sought to gauge the effects of risk to one's employment status. Whilst individual findings vary, the overall message from this research is that job insecurity has independent detrimental effects on employees' physical and mental health, sense of well-being and

25 For example, Hacker, Rehm and Schlesinger 2013; Rehm, Hacker and Schlesinger 2012; Schwander and Häusermann 2013. 
attitudes towards their job and organization. ${ }^{26}$ Indeed, some studies report that the negative effects of job insecurity exceed those of job loss. For example, in their longitudinal study of a large Australian organization in which jobs were under threat, Dekker and Schaufeli conclude that 'certainty about a job situation (even if that is the unpleasant certainty of having been made redundant) is less detrimental to a worker's psychological health than a situation of prolonged job insecurity'. ${ }^{27}$

What about the impact of economic insecurity on self-respect specifically? We have not identified any existing studies that directly set out to test this issue. However, there are related findings from the job insecurity literature that speak to the question of selfrespect. Specifically, several studies report that insecurity tends to lead to job and organizational withdrawal or 'disinvolvement syndrome': a decrease in the extent to which employees feel involved in, committed to or proud of their organization and their work. ${ }^{28}$ The workplace is an arena in which many people find worth and meaning in their lives, and job insecurity tends to diminish these positive attitudes and attachments. Thus the limited available evidence suggests that insecurity at work threatens an important element of self-respect.

26 On adverse health effects, see Burgard, Brand and House 2009; Ferrie et al. 1998. On well-being and job attitudes, see Nolan, Wichet and Burchell 2000. For a meta-analysis taking in a range of independent variables, see Sverke, Hellgren and Näswall 2002, 242-64.

27 Dekker and Schaufeli 1995, 61.

28 For example, Dekker and Shaufeli 1995, 58 and 60-61. Research suggests that there is an emotional component to disinvolvement syndrome, which goes beyond the rational reallocation of attention and motivation under conditions of insecurity. 
We use data from the 2011 wave of the Health Survey for England (HSE) ${ }^{29}$ to build on this existing research. The HSE is a major public survey, focused primarily on population health. It includes questions on occupation and perceptions of job security, which we use to construct three measures of economic risk (two measures of job insecurity and one measure of income insecurity). The HSE also contains items that enable us to construct an index that captures the philosophical notion of self-respect more closely than existing studies. In 2011, although not in either of the more recent waves, there is also a question about whether respondents enjoy taking risks. This allows us to investigate the more positive side of risk that is highlighted in the qualitative studies discussed in Section E. Thus, we use the 2011 data in preference to more recent years. The full sample is just over 10,000 respondents. However, as we are interested in risks associated with employment we limit our analyses to those currently in work and most of our analyses contain around 4000 individuals.

Since we take Tomasi as our starting point, we follow him in focussing on Rawlsian selfrespect. ${ }^{30}$ This involves two key elements: first a sense of our own worth and the value of our commitments and life plans and, secondly, confidence in our ability to hold

${ }^{29}$ Joint Health Surveys Unit of NatCen Social Research and the Research Department of Epidemiology and Public Health at UCL (University College London) 2011.

30

Tomasi takes up Rawls's conception of self-respect at Tomasi 2012, 82. More generally, many of Tomasi's arguments involve an internal critique of Rawls; he contends that Rawlsian-liberals mistake the economic requirements for the realisation of their own values. In particular, he charges Rawls with 'unjustified exceptionalism' in his account of the basic liberties and contends that 'the same reasons that high-liberals offer in support of their preferred economic liberties apply with at least as much force to the aspects of economic freedom they wish to exclude', Tomasi 2012, 76. Thus Tomasi's claim about the relationship between risk and self-respect is most plausibly interpreted in terms of the Rawlsian notion of self-respect. 
ourselves to our standards and to pursue our plans. ${ }^{31}$ At times, Tomasi does seem to be working with an idea of self-respect that is more moralized than Rawls's. For example, he claims that a person's self-respect is diminished when others provide her with 'material means', 32 but he is apparently unconcerned that transfers within families might threaten self-respect. This raises the suspicion that Tomasi has, at this point, lapsed into a moralized notion of self-respect that assumes a prior theory of rights: a theory according to which people have a right to inherit from family members but not to extensive state provision. However, this moralized notion is problematic given the justificatory purpose that the idea of self-respect is intended to fulfil. Specifically, the appeal to self-respect is supposed to do work in showing that a wide array of economic freedoms should be elevated to the status of basic liberties. Thus Tomasi must resist the temptation to define self-respect in terms of the system of rights it is supposed to justify. $^{33}$ Rawls's conception of self-respect is suitably non-moralized for Tomasi's purposes, since it does not build in a specific account of the basic liberties.

Using the HSE, we identify respondents as either having or lacking self-respect based on their answers to questions about whether they feel good about themselves, and feel useful (corresponding to the dimension of self- and plan-worth) and about their confidence and ability to deal with problems (corresponding to belief in their ability to pursue their chosen life plan). To be coded as having self-respect, respondents must

31 Rawls 1999, 386.

32 Tomasi 2012, 83.

33 Cf. Massey's critique of Feinberg - Massey 1983, 257. 
report feeling good about themselves, useful, confident and dealing with problems well, either 'often' or 'all of the time'. ${ }^{34}$ It might be objected here that feeling good about myself is not the same as having a sense of my worth and the worth of my plans. For example, I could have positive feelings about myself because of something I have achieved, whilst lacking the more basic sense of my worth as a person that is a key element of self-respect. Our response to this worry is partly conceptual and partly empirical. On the conceptual side, feeling good about oneself and feeling useful together capture at least part of the Rawlsian notion of self-worth. Whilst the measures are not perfect, they come closer than any existing outcomes in the literature on risk and they represent an improvement on speculative claims about the social bases of selfrespect. On the empirical side, other studies report a strong correlation between indicators of positive feelings about oneself and indicators of self-worth. ${ }^{35}$ This provides some reassurance that our results are not substantively different from those that would be obtained with a more direct measure of 'worth as a person'.

34 We choose this binary operationalisation as it most closely matches the original Rawlsian formulation of (adequate) self-respect as something that a person may either have or lack. However, the results presented here are substantively identical if we use an index measure, where answers to each of the four questions above contribute to self-respect in an additive way (with responses of 'None of the time' scoring 1; 'Rarely', 2; up to 'All of the time', 5). A second issue is that the philosophical notion of self-respect is perhaps not closely tied to the frequency of feelings as measured in the survey items. However, in applied work on similar concepts, '[t]here is... tentative evidence that asking respondents to recall the frequency of their emotional experiences may produce more accurate reports than intensity judgements', OECD 2013, 75. There is no obvious reason to expect self-respect to differ in this regard.

Diener, Suh, Lucas and Smith 1999; Schimmack and Diener 2003. 
Our analysis begins with two measures of unemployment risk. Our first measure is the subjective probability individuals ascribe to losing their job and becoming unemployed in the next twelve months. Respondents are asked to identify their risk on a scale from 0 to 100 where zero indicates that the change will definitely not occur, and 100 that it definitely will. This subjective measure captures the theoretical concept of interest, since individuals typically need to be aware of the relevant risks they are facing for these risks to affect self-respect. ${ }^{36}$ However, in empirical terms we might be concerned about using subjective risk perception to identify the links between risk and self-respect, since in this formulation we are simply correlating attitudes with other attitudes. In this type of relationship it is very difficult to be confident that any relationship runs in the causal direction that we have in mind. It might be that low self-respect leads to more pessimistic assessments of unemployment risk. Alternatively, some other kind of attitude - a high degree of risk aversion, for example - might shape both risk perceptions and self-respect. To guard against this possibility we therefore also use a measure of unemployment risk that is derived from the objective economic position of the respondent. We know the gender and occupation of each of our respondents in the HSE, and can match that data to Office for National Statistics measures of the unemployment rates faced within those gender-occupation groups in the population. We use this gender-occupation unemployment rate as an objective measure of the risk of unemployment. In applying this objective measure we are not assuming that there is

36 It is possible for a risk that is unrecognized by me to impact on my self-respect if others are aware of my insecure position and, as a result, treat me in ways that affect my self-respect. However, such cases will be rarer. 
some mechanism by which objective risk can impact self-respect without running through subjective risk. Rather we are measuring the component of subjective risk that is accounted for by the objective reality of an individual's employment situation.

The results below come from statistical models that include controls for income, gender, age and its quadratic, as well as indicator variables for self-employed respondents. Thus we are able to isolate insecurity from other material and social bases of respect. Figures 1 and 2 plot the expected probabilities of a typical respondent enjoying self-respect, as risk changes. ${ }^{37}$ For both subjective and objective unemployment risk, there is a strong negative relationship: as risk increases, the likelihood of enjoying self-respect declines. ${ }^{38}$ Whilst our primary agenda is philosophical, these results also resonate with recent work in political economy. Specifically, the finding that economic risk is negatively related to self-respect is readily comprehensible in light of the known political consequences of risk: those faced with increasing risk tend to demand more of the very social insurance programmes that Tomasi criticises. ${ }^{39}$

\section{[[ Figure 1 about here ]]}

37 The 'typical' respondent is constructed by holding the control variables constant as risk changes. We hold income and age at their average (mean) values in the data used for the model, and consider a male respondent, not self-employed.

38 As a reviewer has pointed out to us, there is a question about how we best interpret Tomasi's claim that risk is a 'precondition' of self-respect. Strictly, this might be understood as the claim that we need some (non-zero) degree of economic risk in order to enjoy self-respect. Here we test the claim that increased risk leads to a greater likelihood of an individual having self-respect. This seems to us a more plausible way of reading Tomasi's 'precondition' claim, given that the vast majority of individuals will experience some degree of economic risk. 
Figure 1. Expected probabilities of a typical respondent reporting having self-respect as self-reported chance of job loss increases. Shaded areas indicate 95\% confidence intervals.

[[ Figure 2 about here ]]

Figure 2. Expected probabilities of a typical respondent reporting having self-respect as occupation-gender specific unemployment risks increase. Shaded areas indicate $95 \%$ confidence intervals.

Our third measure of economic risk draws on a large recent literature in the political economy of skills, which highlights that investing in skills that are specific to particular jobs, firms, or industries exposes the worker to greater risk than a similar investment in more general skills. If skills are specific to a particular industry or firm, then workers face the risk of income loss if that industry goes into decline: the premium paid for specific skills is (by construction) not available outside the particular industry. Compared to a worker at the same level of pay, but whose skills are general, the specific skill worker faces higher levels of risk. ${ }^{40}$ Specific skills - and the associated risk of income loss - are measured with reference to the specialisation of skills within occupations. The measure is based on the International Labour Organisation classification of jobs into occupations in the International Standard Classification of Occupations (ISCO) coding scheme. The scheme uses the level and specialisation of skills involved in different occupations to group them into categories at varying levels of similarity. The smallest occupational

40 Iversen and Soskice 2001. 
groupings consist of 390 classes or 'unit groups', each with a high level of homogeneity in terms of their required type of knowledge, tools and equipment, the materials worked on, or with, and the goods and services that are produced. These unit groups are aggregated into broader categories, up to nine major groups at the highest level. The specificity of skills within any higher level group can then be measured by the number of different unit groups of which it is comprised. ${ }^{41}$

Considering skill specificity helps to solve two (related) problems in determining the link between risk and self-respect. First, it makes the possibility of reverse causation less plausible: Low self-respect might lead to higher perceived unemployment risk and perhaps even to a greater likelihood of entering objectively less secure occupations; taking on the risk associated with investment in specific skills is not so easily thought of as a consequence of low self-respect. Secondly, the specific-skill measure eliminates the link between risk and general disadvantage. For example, the lowest levels of specificity are found in sales and customer service, and administrative and secretarial occupations; the highest in skilled and - particularly-semi-skilled trades. These occupations have similar, intermediate, levels of pay and status, yet have very different risk profiles based on skill specificity.

[[Figure 3 about here]]

41 The measure is actually the number of unit groups relative to the size of the population employed in the higher-level groups. A full explanation of the measure can be found at: http://www.people.fas.harvard.edu/ iversen/SkillSpecificity.htm\#Explanation 
Figure 3. Expected probabilities of a typical respondent reporting

having self-respect as the risk associated with specific skills

changes. Shaded areas indicate $95 \%$ confidence intervals.

Figure 3 shows that the negative relationship between risk and self-respect is still apparent when considering skill-based risks. The detrimental impact is smaller, but higher risks are still (statistically significantly) associated with lower self-respect. ${ }^{42}$

\section{B. CAUSAL INFERENCE}

Interpreting the relationships in the cross-sectional data as causal is valid only if, conditional on the included covariates, those experiencing high levels of risk are good counterfactual observations for those at low levels of risk. Whilst there are strong theoretical reasons to assume a causal relationship from risk to self-respect in the associations we report, we can never fully defend against problems of endogeneity when comparing across individuals. ${ }^{43}$

Panel data allow us to solve this problem by considering only variation in risk-exposure and self-respect over time within the same individuals. In the appendix we present an

42 In fact, this figure may understate the negative impact of skill-based risk on self-respect. The model used to generate this figure does not include controls for occupation, because the skill specificity variable itself is defined at the occupational level. But there are good reasons to think that the kinds of occupations that require highly specific skills, or the individuals who undertake those occupations, may have other characteristics that promote self-respect. For example, this kind of investment in skills for the long run implies a commitment to a particular life plan. In the analyses, the risk measure will also pick up the (offsetting) effects that this dynamic has on self-respect.

${ }^{43}$ See the appendix for an extended discussion of the arguments for and against reverse causation and spurious association in the cross-sectional data. 
analysis of the British Household Panel Survey (BHPS) ${ }^{44}$, which shows how changes in risk-exposure relate to over-time changes in self-respect. Consistent with our crosssectional results, we find that higher risk (operationalised using objective unemployment risk) is associated with lower levels of self-respect. That is, when individuals are experiencing periods of relatively high unemployment risk, they are less likely to report self-respect. Thus the panel data analysis bolsters the case for a (negative) causal relationship between risk-exposure and self-respect. ${ }^{45}$

\section{NON-LINEAR EFFECTS OF RISK}

The specification of the models in the main analyses assumes a linear relationship between risk and self-respect. ${ }^{46}$ That is, any increment of risk is modelled as having the same (it turns out negative) effect on self-respect. But perhaps this linear picture is not the most realistic representation of how risk is experienced, or indeed a good representation of Tomasi's claim that risk is a 'precondition' of self-respect. ${ }^{47} \mathrm{~A}$ more

${ }^{44}$ University of Essex Institute for Social and Economic Research 2010

${ }^{45}$ Given the superiority of panel data for causal inference, a few words on why we nevertheless focus on the cross-sectional data are in order. First, the measure of the self-respect outcome available in the BHPS is inferior to that in the HSE. Secondly, there is no available measure of subjective unemployment risk, which is our preferred measure of risk. Finally, the incidental parameters problem associated with estimating within-individual effects with a binary outcome means that the substantive effect sizes in the panel data are much less intuitive: we cannot generate and compare predicted probabilities under differing levels of risk in a straightforward way.

46 Technically the models are linear between risk and the linear predictor of self-respect which is then transformed via the logistic specification into a value between zero and one. In what follows we are interested in the shape of this underlying function relating risk to the linear predictor.

47 We thank two anonymous reviewers for pressing us to consider a non-linear relationship between risk and self-respect. 
conservative interpretation might imply an inverted-U shape, such that low levels of risk increase self-respect, but the relationship reverses after a certain point. The intuition here is that relatively small amounts of risk might be motivating or empowering, even if risk beyond a certain level tends to become threatening or overwhelming.

We can address this question empirically in the HSE data, through the specification of different functional forms. We do find some non-linearity, but there is no evidence of the inverted-U, which would imply a benefit to risk at low levels. Specifically, considering each 0.1 increment of (self-reported) risk as a separate category indicates that the negative effects in the linear model are driven by people reporting chances of job loss at or above 0.3 . The effect on self-respect of subjective risk below this level seems to be essentially zero. On the one hand this is good news for risk. At low levels it has no negative effect and this area of the subjective risk scale is where most people rate their exposure: $57 \%$ of respondents are in the lowest three categories $(0,0.1,0.2)$. However, there is no level of risk at which risk benefits self-respect and $43 \%$ of people remain exposed to levels of risk which appear to be harmful to self-respect. Further details, and analysis of non-linearity with the objective risk measures, can be found in the appendix.

Linear specifications also imply that the effect of risk is the same for everyone, when we might expect that different circumstances will lead to varying effects of any given increment of risk. In particular, some people may be better able to cope with risk because of their capacity to draw on other resources. Two examples of such buffering resources, for which we have empirical measures, are income and the presence of an 
adult partner in the household. Both of these factors might lessen the impact of employment insecurity on self-respect by increasing the likelihood that the individual has a material cushion to fall back on. It also seems plausible that having a partner might directly mitigate the psychological effects of the threat of economic loss. However, in our data we find no evidence of this kind of differential impact (in models interacting subjective risk with income, or with a simplified version of marital status which separates those who are married or cohabiting from the single, separated and divorced).

The shape of the relationship between risk and self-respect is further complicated by the distinction between absolute and relative risk. For example, imagine a society in which everybody faces a high risk of bad economic outcomes. Should we expect the consequences for self-respect to be the same as for a high-risk subgroup in an otherwise economically more secure society ${ }^{48}$ Relatedly, does the impact of economic risk on selfconcept stem primarily from the dynamics of power and control that typically accompany real-world risky situations? Or is self-respect also threatened by economic uncertainty itself - uncertainty effects that remain present in contexts of equal risk ${ }^{49}$ We are unable to tackle these questions in a systematic way using our quantitative data, since our methodology relies on the existence of inequalities in economic risk in order to estimate the impact of absolute risk levels. In other words, our results tell us about the

48 We thank Adam Swift for raising the distinction between absolute and relative risk.

49 The example of the insecure tenant, with which we began the paper, involves vulnerability to the power of a landlord as well as uncertainty about the future. The relationship between economic insecurity and domination is widely discussed in the republican literature. See, for example, Pettit 2007. 
impact of differing levels of economic risk in a context of unequal risk. However, we can draw some tentative hypotheses based on the mechanisms linking risk and self-respect outlined in section I. Specifically, it is likely that the social meaning of risk will differ according to whether risk is something that affects everybody, or only a subset of the population. On the other hand, it seems plausible to us that the psychological and behavioural connections between risk and self-respect are at least partly independent of the distributive question.

\section{RISK OR OVERCOMING ADVERSITY?}

In this section we consider an alternative, and potentially more generous, interpretation of Tomasi's claim that risk is a precondition of self-respect. In particular, we might think that risk benefits self-respect in the sense that leaving individuals to face risk also allows them to experience the self-respect benefits of triumphing over adversity. Understood in this way, Tomasi's claim is less about the benefits of the experience of risk itself and more about the sense of resilience or confidence that stems from having faced unfavourable outcomes in the past and overcome them. ${ }^{50}$

Using the BHPS, we investigate whether having experienced economic adversity, but come out of it well, increases self-respect. First, each survey period is categorised as a good or bad outcome state in terms of labour market position. Periods where

50 We thank two anonymous reviewers for drawing our attention to this alternative interpretation of Tomasi. To evaluate this argument more fully we would also need to consider the effects on the selfrespect of those who do not bounce back. But here we focus on whether there are self-respect benefits for those who do succeed in overcoming adversity. 
respondents are unemployed, long-term sick, disabled, or on a government training scheme are classed as bad outcomes. Employment and self-employment are coded as good outcomes, whilst periods of maternity, retirement and family care, as well as being a student, are omitted from the analysis by virtue of their ambiguity. At each point in time, we code whether each respondent has successfully come out of a previous bad outcome: if they have both a bad period (as described above), and a subsequent period in employment or self-employment. We find no evidence that having successfully resolved an adverse labour market situation in the past improves self-respect. Moreover, the 'instantaneous' effect of being in the bad state has consistently negative effects. Thus we find no support even for the looser, more intuitive interpretation of Tomasi's argument as concerned with the self-respect benefits of overcoming hardship. Our results here resonate with research showing that past unemployment has long-term negative consequences for individual happiness and mental health. ${ }^{51}$

\section{E. THE BENEFITS OF CULTIVATED RISK-TAKING}

The best available evidence suggests that economic risk has a negative impact on selfrespect. However, Tomasi's claim that risk underpins self-respect is not wholly without empirical support. In particular, there is qualitative evidence showing that the experience of risk can have a positive impact on individual self-concept. For example, Lupton and Tulloch conducted a series of in-depth interviews with Australian and British participants about how they understand risk and how it shapes their lives. Participants

51 Winkelmann and Winkelmann 1998; Daly and Delaney 2013. 
described important benefits of risky experiences. Moreover, some of the ways in which they characterized the value of risk resonate with Rawlsian self-respect. For example, some participants appealed directly to the related notion of self-esteem. Others talked about self-improvement, an increased sense of control and a sense of agency. In summary, 'Cultivated risk-taking ... is seen to provide an opportunity for individuals to display courage, to master fear, to provide something to themselves which allows them to live life with a sense of personal agency'. ${ }^{52}$ Lupton and Tulloch's study coheres with a broader tradition of qualitative research that reports individual-level benefits of risky experiences. For example, in his widely cited account of 'edgework', Lyng emphasizes the sense of self-actualization, self-determination and confidence derived through the confrontation of risk. $^{53}$ Similar themes have emerged from studies of risk-taking in criminology. For example, in his classic Seductions of Crime, Katz describes how 'hardmen' robbers gain a sense of agency and control by creating order within high-risk situations: 'chaotic situations ... are transformed into courses of action that make selfrespecting sense through the imposition of the form and discipline of a stickup'. ${ }^{54}$

Thus there is evidence from a number of disciplines and domains that supports the claim that the experience of risk can promote positive self-attitudes. But what, if anything, does this research say to Tomasi's claim about the value of exposure to economic risks? The reference to 'cultivated risk-taking' in the passage from Lupton and Tulloch is crucial.

52 Tulloch and Lupton 2003.

53 Lyng 1990, 860 and 863.

54 Katz 1988, 225. 
Their interviews covered a range of experiences, including speaking out on controversial subjects and deciding to migrate, as well as risky sports and leisure activities. However, these diverse activities had a key feature in common: each involved the individual making a deliberate and voluntary decision to expose herself to risk. Similarly, Lyng introduces the notion of edgework to capture a form of high-stakes voluntary risk-taking. In contrast to these accounts, Tomasi appeals to self-respect to make a case for widespread exposure to involuntary risk in the economic sphere. On Tomasi's account the experience of risk is not something to be sought out by a minority of individuals; rather 'Risk is to become a daily necessity shouldered by the masses'. ${ }^{55}$ Importantly, providing people with a baseline of security is often the best way of enabling voluntary risk-taking (and its self-respect benefits). Thus if our goal is to increase self-respect enhancing risk-taking (rather than simply to put people at economic risk), social democratic regimes are likely to outperform models closer to Tomasi's ideal of market democracy. ${ }^{56}$

We conclude that the view of risk underlying Tomasi's account has some empirical weight, but not in the context to which Tomasi applies it. However, research into cultivated risk-taking might offer a way of partially rehabilitating Tomasi's argument: if some people are more inclined towards risk-taking than others, perhaps for these riskloving individuals the experience of economic risk is an important precondition of self-

55 Sennett 1998, 80.

56 On the importance of security as a precondition for risk-taking, see Hacker 2008. For empirical evidence linking greater social spending to risk-taking, see Bird 2001, 357-83. 
respect? For Rawls, the social bases of self-respect concern those conditions 'normally essential' for a lively sense of self-worth and confidence. ${ }^{57}$ But perhaps there are significant limits to our ability to generalize about the relationship between risk and selfrespect? The HSE data support the first step in this argument: individuals do differ in the extent to which they report enjoyment of risk-taking and there is a positive relationship between enjoyment of risk-taking and self-respect. ${ }^{58}$ Crucially, however, the enjoyment of risk-taking does not mediate the relationship between economic insecurity and selfrespect. In other words, economic insecurity has a similarly negative impact on selfrespect even for those individuals who express more favourable attitudes towards risktaking. This feature of the data is shown in Figure 4, which displays the expected levels of self-respect as subjective unemployment risks increase (as in Figure 1), but differentiates the expectation depending on the individual's attitude towards risk. ${ }^{59}$

[[ Figure 4 about here ]]

Figure 4: Expected probabilities of a typical respondent reporting having self-respect as subjective unemployment risk changes. The

57 Rawls 2001, 59. Emphasis added.

58 There is a large amount of research into variation in attitudes towards risk and propensity for risktaking. For a classic account in the 'personality types' tradition, see Balint 1987, Chapter 2. On demographic factors, see Finucane et al. 2000, 159-72. For an account that emphasizes socioeconomic position, see Lyng 1990, 876-77 and 882-3.

59 The expected values come from a regression model equivalent to those in Section II.A, but with an added term, the interaction of risk-orientation and subjective unemployment risk, which allows the effect of unemployment risk to vary according to risk preference. Risk attitudes are measured via the level of agreement with the statement 'I get a lot of pleasure out of taking risks', with 7 possible responses ranging from 'Disagree strongly' to 'agree strongly'. The two categories used to create Figure 4 represent the interquartile range of responses to this question. 
solid line shows the probabilities for those who enjoy taking risks, the dashed line those who do not. Shaded areas indicate 95\% confidence intervals.

\section{CHARACTERISTICS OF RISKY EXPERIENCES}

We have reported a divergent set of findings about the relationship between risk and self-respect. In the economic sphere, both the existing evidence about job insecurity and our own analyses of the HSE and BHPS suggest that risk is damaging to self-respect. On the other hand, there is an established body of qualitative research showing that individuals who participate in a variety of forms of risk-taking find this activity to be beneficial to their sense of worth and confidence. As discussed above, the extent to which risks are voluntarily confronted is perhaps the most obvious feature that accounts for this pattern of results. ${ }^{60}$ The significance of voluntariness is reinforced by research showing that the benefits of risk are often experienced at the moment of deciding to risk, rather than through the ongoing experience of insecurity. ${ }^{61}$ Part of what is valuable to us about experiencing certain forms of risk is the opportunity to see ourselves as people who are willing to confront and to choose risk, and this value is lacking in contexts of imposed risk.

The more general thought here is that risky situations differ along a number of crucial dimensions that affect how risk is experienced, including the relationship with self-

60 But for doubts about the importance of voluntariness as a factor shaping public assessments of the acceptability of risk, see Slovic, 146-48.

61 See Sennett 1998, 87. 
respect. Risk itself plays an important role in delivering the self-respect benefits highlighted in the literature on cultivated risk-taking: It is in part the fact of not knowing what the future will look like (and sometimes the sense of danger this brings) that activates people's sense of agency. However, the self-respect benefits of risk are conditional on some key features of the context. In addition to voluntariness, we should consider the extent to which risk permeates everyday life or is contraposed with the everyday. ${ }^{62}$ On this dimension of pervasiveness, economic insecurity again looks very different from the forms of risk that qualitative research has identified as beneficial. For example, for the skydivers in Lyng's study, a sense of contrast with the everyday constituted an important part of the value of risk. ${ }^{63}$ Thirdly, risks vary in the extent to which they are experienced as controllable or as determined by forces beyond the individual's control. For example, think about playing the lottery compared to mountaineering (for the experienced climber!); they involve very different forms of risk in this regard. The extent to which the benefits of risk stem from the sense of control also emerges strongly in Lyng's research. In addition to the specific skills involved in the activity of skydiving, his 'edgeworkers' valued the exercise of the generalized capacity to maintain control in the face of potential disaster. ${ }^{64}$ Moreover, they commonly eschewed risks that they perceived as pure gambles: 'What they seek is the chance to exercise skill

\footnotetext{
62 Cf. Giddens 1991, 132. Giddens runs these two dimensions of voluntariness and pervasiveness together.

63 Lyng 1990, 861 and 880-81.

64 Lyng 1990, 859-60 and 871.
} 
in negotiating a challenge rather than turn their fate over to the roll of the dice ${ }^{65}$ The broader message is that the experience of risk is more likely to increase our sense of worth or confidence to the extent that we perceive the situation to offer us some degree of control and the opportunity to exercise our skills.

We are concerned here with perceptions of control, and the distinction between risks felt to be controllable and those experienced as determined by outside forces is not clearcut or completely stable: studies suggest that we sometimes attribute control in activities that are, from an objective perspective, clearly pure gambles. ${ }^{66}$ Nevertheless, the distinction between gambles and skilled leisure pursuits provides a useful starting point for thinking about divergent experiences of risk. But what does this imply for the domain of economic risk? For most of us, the experience of economic life probably lies somewhere between these two poles in respect of the degree of felt control. Thinking about the economic domain in terms of a spectrum of perceived control can help to account for an as-yet unaddressed complication in Lupton and Tulloch's findings. Whilst we have emphasized the contrast between cultivated risk and economic risk, a small subset of participants in this study drew parallels between risk in their leisure and economic lives, and described the latter as similarly enjoyable and empowering. ${ }^{67}$ Underlying the more positive experience of economic risk amongst this subgroup of hi-

65 Lyng 1990, 863.

66 For a classic account, see Langer 1975. Relatedly, Lyng notes that when accidents occur, skydivers do not conclude that the dead or injured were unlucky. Rather, this is taken as evidence that they lacked the necessary survival skills - see Lyng 1990, 874.

67 Tulloch and Lupton 2003, 75 and 78. 
tech workers was a strong sense of control, driven by the belief that their skills enable them to negotiate increasingly challenging labour markets. This contrasts with the experiences of a group of car workers, who reported a lack of control in the face of decision-making by large corporations. Further research would help to build on these findings. For example, it has been suggested that the presence of factors typically associated with skill situations, such as planning and organization, increases the perception of control in contexts where outcomes are, in fact, determined by outside forces. ${ }^{68}$ Are these features particularly strongly present for those who experience economic risk in more positive terms?

A fourth important way in which risky situations differ concerns the nature of the stakes. However, here the implications for self-respect are less clear. We might assume that risk is more likely to threaten self-respect when the potential losses are severe. However, some of the classic examples of cultivated risk-taking, through which participants report gains to self-respect, involve the very highest stakes: physical health or even life itself. We do not have the empirical evidence necessary to test this issue directly. However, it seems likely to us that the impact of the size of the stakes will be that of a multiplier: where the other dimensions of risky contexts (voluntariness, non-pervasiveness and sense of control) lead to a positive experience of risk, higher stakes will reinforce this benefit; but a negative experience of risk will be exacerbated by high stakes.

68 Lyng 1990, 875-76. 
Further work is needed to build on this picture of the key dimensions of risky experiences. For example, our quantitative estimates cannot capture ways in which the social and psychological meaning of risk may vary across individuals, or over time. However, the available evidence supports the following hypotheses: first, the experience of risk enhances individual self-respect to the extent that risks are experienced as voluntary, non-pervasive and controllable; secondly, the size of the stakes reinforces the above relationships. Although our empirical analysis is restricted to three measures of economic insecurity, these hypotheses allow us to offer some tentative thoughts about the relationship between self-respect and further forms of risk. For example, consider insecurity in access to healthcare; a politically important aspect of risk that differs significantly between regimes. Along the dimensions of voluntariness, pervasiveness and controllability, risk to healthcare lies much closer to job and income insecurity than to the various examples of cultivated risk-taking. Thus we would expect the relationship between healthcare insecurity and self-respect to follow the negative pattern demonstrated in the HSE and BHPS. ${ }^{69}$

\section{EMPIRICAL POLITICAL PHILOSOPHY}

We have seen that researchers from a range of disciplines are increasingly turning their attention to questions about the nature and impact of economic insecurity. Thus it is perhaps surprising that Tomasi does not seek to ground his argument empirically.

69 As an anonymous reviewer has pointed out, economic risk itself may vary in ways we do not capture here. For example, perhaps risk is experienced differently in our roles as economic producers and consumers? Given the data available to us (which concerns employment and income risk), we cannot address this question within the scope of the paper. 
However, Tomasi is not alone in allowing his claim about the preconditions of selfrespect to float free of empirical evidence. Much of the discourse around the social bases of self-respect in political philosophy has a similar character. For example, it is a fundamental tenet of philosophical writing on self-respect, following Rawls, that selfrespect is strongly dependent on others' affirmation of our worth. But this claim is typically advanced without reference to psychological studies of the complex relationships between our self-concept and how others respond to and evaluate us. ${ }^{70}$ This tendency is also evident in recent work on property-owning democracy, which involves some speculative claims about how the organization of the economy shapes individual self-respect. ${ }^{71}$ What explains the disconnect between philosophical and empirical work? Do we simply need to do more to overcome the challenges of working across disciplinary boundaries? Or are there, in fact, good reasons for wanting to maintain the divide?

Our empirical approach to the question of the relationship between risk and self-respect faces the following objection: we have investigated the economic conditions under which people actually tend to derive self-respect in the here and now. But what if these responses are contaminated by the effects of non-ideal background conditions, or are in

70 See, for example, Gecas and Schwalbe 1983.

71 For example, Martin O'Neill asserts that “Only by making sure that the structure of the economy is such as to broadly disperse control over productive resources ... can we ensure that all citizens are able to have [self-respect]." But he does not bring forth empirical evidence about the relationship between self-respect and control over productive resources. See O'Neill 2012, 75-100. 
some other respect 'unreasonable' ${ }^{72}$ Are we then similarly contaminating our theory? For example, Lyng suggests that 'edgework' is, in part, a response to a lack of opportunities for self-determination and self-actualization within modern working life. ${ }^{73}$ Thus although 'edgeworkers' do, in fact, gain in self-respect from their risk-taking activities, if Lyng is correct then there is something problematic about the conditions giving rise to this effect.

We have two responses to this kind of worry. First, insofar as we are offering an internal critique of Tomasi, the empirical strategy is appropriate. Tomasi presents his theory as building out of observation of the actual concerns and experiences of citizens in advanced post-industrial societies. However, he does not engage with data in the way necessary to make good on this methodological vision. Secondly, and more generally, if we want the notion of self-respect to play an independent role in our theory, then we do best to start by looking at the actual social bases of self-respect. What are the alternatives? The first is pure speculation about where citizens would get self-respect under more ideal conditions. We have already seen that it is possible to construct contrasting, yet plausible sounding stories about the relationship between risk and selfrespect. To move beyond this storytelling, we need empirical evidence. Of course the

72 The 'unreasonableness' objection takes at least two distinct forms. Often what is meant is that a particular way of deriving self-respect necessarily makes self-respect unavailable to some people, by attaching self-respect to an inherently competitive or comparative characteristic (e.g. relative height). In a second form, the objection holds that a means of deriving self-respect may be generally effective, but is, in some other terms, undesirable. For example, Doppelt expresses both of these concerns without clearly distinguishing them - see Doppelt 2009, 141-3.

73 Lyng 1990, 871 and 876-77. 
sources of self-respect might change with social and political conditions, but utilizing empirical evidence is the best way of developing some plausible hypotheses about how self-respect would behave in different contexts. Thus although Tomasi could respond that he is making a claim about the social bases of self-respect under counterfactual conditions of free market fairness, he would need to show why we should expect the current relationship with economic risk to be reversed. We do not find such an account in Tomasi.

The second alternative to empirical investigation is philosophical assertion about where people ought to get self-respect. But if we push the 'unreasonableness' objection too far in this direction, we become vulnerable to the objection that self-respect is no longer contributing anything to the specification of the conditions of a just society, rather it is parasitic on a prior theory of justice. Once we have understood how self-respect is actually derived, we might subsequently identify certain of these patterns as problematic. Hence our empirical approach does not foreclose the possibility that we should seek to reshape some aspects of the social bases of self-respect, rather than accepting them as given (although again empirical evidence is required to tell us about the likely success of any such strategy). We do not claim that empirical evidence of the kind brought forth here should have the last word in philosophical argument about the social bases of self-respect. But it does provide an important starting point.

\section{CONCLUSION}


In his account of the changing nature of modern working life, Richard Sennett describes a business manual that 'domesticates the heroism of risk'; it depicts a world of work in which risk 'becomes normal and ordinary' ${ }^{74}$ Sennett's observation nicely captures the mistake in Tomasi's view of the relationship between risk and self-respect. Tomasi is right to think that risk can bring important benefits in terms of individual self-concept: research into the phenomenon of 'cultivated risk-taking' bears this out. However, he mistakenly transplants this vision of the value of risk to the economic domain, where risk is typically unchosen and pervasive; often feels uncontrollable and involves high-stakes. In this context, we have shown that the experience of risk tends to undermine rather than support individual self-respect. The wider message of this paper is that we should move beyond the construction of plausible sounding stories about the social bases of self-respect, to engage in the messy empirical business of testing our theories.

\section{REFERENCES}

Barnes, Lucy and Baderin, Alice. 2018. "Replication Data for: Risk and Self-Respect", doi:10.7910/DVN/AUX9W1, Harvard Dataverse, DRAFT VERSION, UNF:6:WykBOgvJzwsQScbuNL9POg==

Balint, Michael. 1987. Thrills and Regressions. London: Karnac Book.

Bird, Edward J. 2001. Does the welfare state induce risk-taking. Journal of Public Economics 80: 357-83.

Burgard, Sarah A., Jennie E. Brand and James S. House. 2009. Perceived job insecurity and worker health in the United States. Social Science and Medicine 69: 777-85.

74 Sennett 1998, 81. 
Cohen, G. A. 2016. Capitalism, Freedom and the Proletariat. Pp. 163-182 in The Liberty Reader, edited by David Miller. Abingdon: Routledge.

Daly, Michael and Liam Delaney. 2013. The scarring effect of unemployment throughout adulthood on psychological distress at age 50: Estimates controlling for early adulthood distress and childhood psychological factors. Social Science and Medicine 80: 19-23.

Dekker, Sidney W.A. and Wilmar B. Schaufeli. 1995. The Effects of Job Insecurity on Psychological Health and Withdrawal: A Longitudinal Study. Australian Psychologist 30: 57-63.

Diener, Ed, Eunkook M. Suh, Richard E. Lucas and Heidi M. Smith. 1999. Subjective WellBeing: Three Decades of Progress. Psychological Bulletin 125: 276-302.

Doppelt, Gerald. The Place of Self-Respect in a Theory of Justice. Inquiry 52: 127-154.

Ferrie, Jane Elizabeth, Martin John Shipley, Michael Gideon Marmot, Stephen Alfred Stansfeld and George Davey Smith. 1998. An Uncertain Future: The Health Effects of Threats to Employment Security in White-Collar Men and Women. American Journal of Public Health 88: 1030-6.

Finkelstein, Claire. 2003. Is Risk a Harm? University of Pennsylvania Law Review 151: 963-1001.

Finucane, Melissa, L., Paul Slovic, C.K. Mertz, James Flynn and Theresa A. Satterfield. 2000. Gender, race and perceived risk: The 'white male' effect. Health, Risk and Society 2: $159-72$.

Gecas, Viktor and Michael L. Schwalbe. 1983. Beyond the Looking-Glass Self: Social Structure and Efficacy-Based Self-Esteem. Social Psychology Quarterly 46: 77-88.

Giddens, Anthony. 1991. Modernity and Self-Identity: Self and Society in the Late Modern Age. Cambridge: Polity Press.

Gourevitch, Alex. 2014. Welcome to the Dark Side: A Classical-Liberal Argument for Economic Democracy. Critical Review: A Journal of Politics and Society 3-4: 290-305.

Gowder, Paul. 2014. Market Unfreedom. Critical Review: A Journal of Politics and Society 3-4: 306-347.

Green, Francis. 2009. Subjective employment insecurity around the world. Cambridge Journal of Regions, Economy and Society 2: 343-63. 
Hacker, Jacob. 2008. The Great Risk Shift: The New Economic Insecurity and the Decline of the American Dream. Oxford: Oxford University Press.

Hacker, Jacob S., Phillip Rehm and Mark Schlesinger. 2013. The Insecure American: Economic Experiences, Financial Worries, and Policy Attitudes. Perspectives on Politics, 11: 23-49.

Iversen, Torben and David Soskice. 2001. An Asset Theory of Social Policy Preferences. The American Political Science Review 95: 875-93.

Jacobs, Elisabeth and Katherine S. Newman. 2008. Rising Angst? Change and Stability in Perceptions of Economic Insecurity. Pp. 74-101 in Laid Off, Laid Low: Political and Economic Consequences of Employment Insecurity, edited by Katherine S. Newman. New York: Columbia University Press.

Joint Health Surveys Unit of NatCen Social Research and the Research Department of Epidemiology and Public Health at UCL (University College London). 2011. Health Survey for England. Available (with registration) from the UK Data Service: https://discover.ukdataservice.ac.uk/catalogue/?sn=7260\&type=Data\%20catalogue . Accessed 11 April 2013.

Katz, Jack. 1988. Seductions of Crime: Moral and Sensual Attractions in Doing Evil. New York: Basic Books.

Langer, Ellen J. 1975. The Illusion of Control. Journal of Personality and Social Psychology 32: 311-28.

Lupton, Deborah and John Tulloch. 2002. 'Life would be pretty dull without risk': voluntary risk-taking and its pleasures. Health, Risk and Society 4: 113-24.

Lyng, Stephen. 1990. Edgework: A Social Psychological Analysis of Voluntary Risk Taking. The American Journal of Sociology 95: 851-86.

Massey, Stephen J. 1983. Is Self-Respect a Moral or a Psychological Concept? Ethics 93: 246-61.

Nolan, Jane P., Ines C. Wichet and Brendan J. Burchell. 2000. Job insecurity, psychological well-being and family life. Pp. 181-209 in The Insecure Workforce, edited by Edmund Heery and John Salmon. London: Routledge.

Oberdiek, John. 2017. Imposing Risk: A Normative Framework. Oxford: Oxford University Press. 
O’Neill, Martin. 2012. Free (and Fair) Markets without Capitalism: Political Values, Principles of Justice, and Property-Owning Democracy. Pp. 75-100 in Property-Owning Democracy: Rawls and Beyond, edited by Martin O'Neill and Thad Williamson. WileyBlackwell: Oxford.

OECD, 2013. OECD Guidelines on Measuring Subjective Well-being. Available from http://dx.doi.org/10.1787/9789264191655-en, accessed June 14, 2015.

Perry, Stephen. 2007. Risk, harm, interests and rights. Pp. 190-209 in Risk: Philosophical Perspectives, edited by Tim Lewens. Abingdon: Routledge.

Pettit, Philip. 2007. A Republican Right to Basic Income? Basic Income Studies 2: 1-8.

Rawls, John. 1982. The Basic Liberties and Their Priority. Pp. 3-87 in The Tanner Lectures on Human Values, edited by Sterling M. McMurrin. Salt Lake City: University of Utah Press.

Rawls, John. 1999. A Theory of Justice. Cambridge, Mass.: Belknap Press of Harvard University Press.

Rawls, John. 2001. Justice as Fairness: A Restatement. Cambridge, Mass.: Harvard University Press.

Rehm, Phillip, Jacob S. Hacker and Mark Schlesinger. 2012. Insecure Alliances: Risk, Inequality, and Support for the Welfare State. American Political Science Review 106: 386-406.

Schimmack, Ulrick and Ed Diener. 2003. Predictive Validity of Explicit and Implicit SelfEsteem for Subjective Well-being. Journal of Research in Personality 37: 100-106.

Schwander, Hanna and Silja Häusermann. 2013. Who is in and who is out? A risk-based conceptualization of insiders and outsiders. Journal of European Social Policy 23: 248-69.

Sennett, Richard. 1998. The Corrosion of Character: The Personal Consequences of Work in the New Capitalism. New York: W. W. Norton \& Company.

Slovic, Paul. 2000. The Perception of Risk. London: Earthscan Publications.

Sunstein, Cass R. 2005. Laws of Fear: Beyond the Precautionary Principle. Cambridge: Cambridge University Press. 
Sverke, Magnus, Johnny Hellgren and Katharina Näswall. 2002. No Security: A MetaAnalysis and Review of Job Insecurity and Its Consequences. Journal of Occupational Health Psychology 7: 242-64.

Tomasi, John. 2012. Free Market Fairness. Princeton: Princeton University Press.

Tulloch, John and Deborah Lupton. 2003. Risk and Everyday Life. London: SAGE Publications.

University of Essex. Institute for Social and Economic Research. 2010. British Household Panel Survey: Waves 1-18, 1991-2009. [data collection]. 7th Edition. UK Data Service. SN: 5151, http://doi.org/10.5255/UKDA-SN-5151-1. Accessed 25 October 2016.

Winkelmann, Liliana and Rainer Winkelmann. 1998. Why Are the Unemployed So Unhappy? Evidence from Panel Data. Economica 65: 1-15.

Wolff, Jonathan and Avner de-Shalit. 2007. Disadvantage. Oxford: Oxford University Press.

Wolff, Jonathan. 2009. Disadvantage, Risk and the Social Determinants of Health. Public Health Ethics 2: 214-23. 
FIGURES

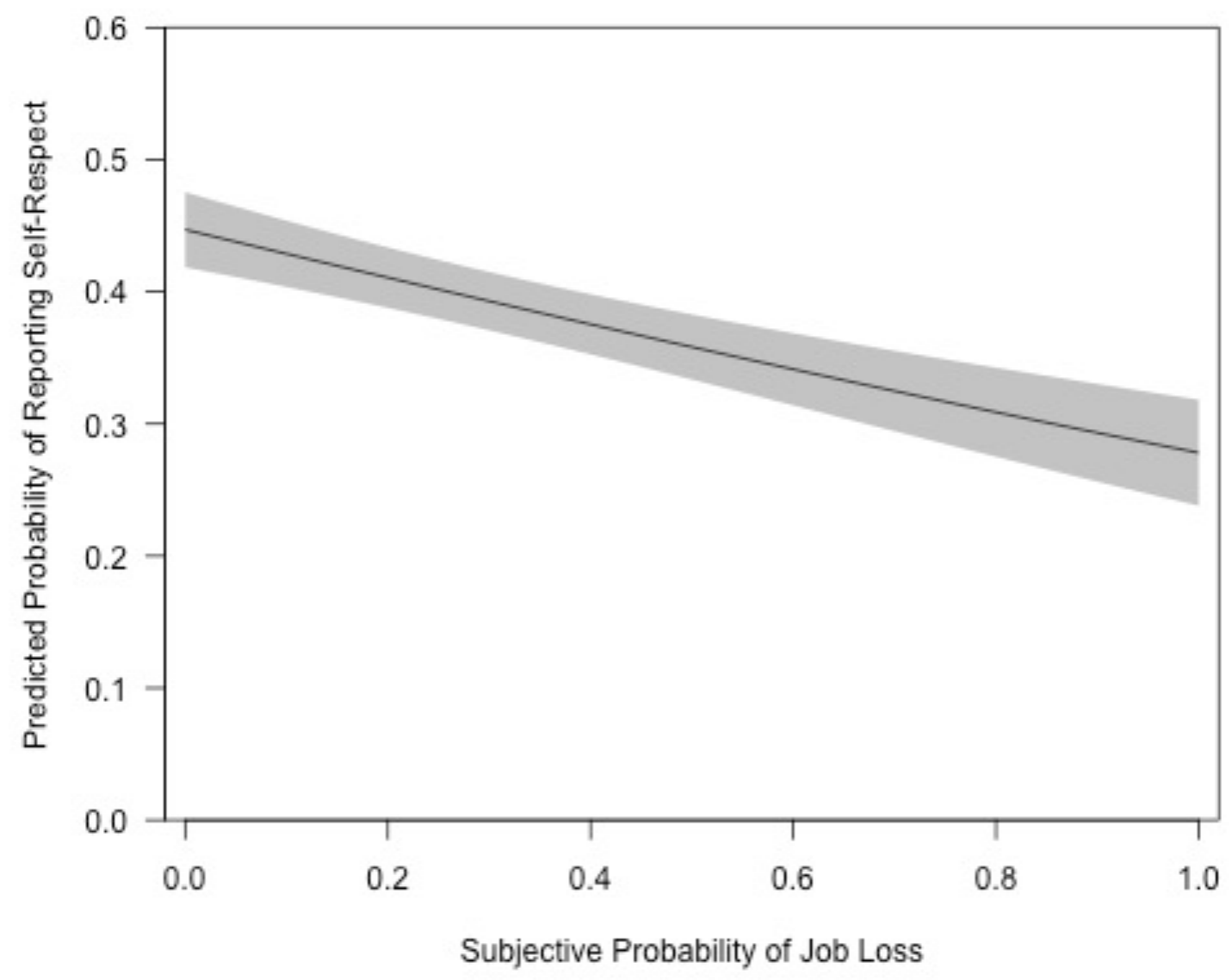

Figure 1. Expected probabilities of a typical respondent reporting having self-respect as self-reported chance of job loss increases. Shaded areas indicate $95 \%$ confidence intervals. 


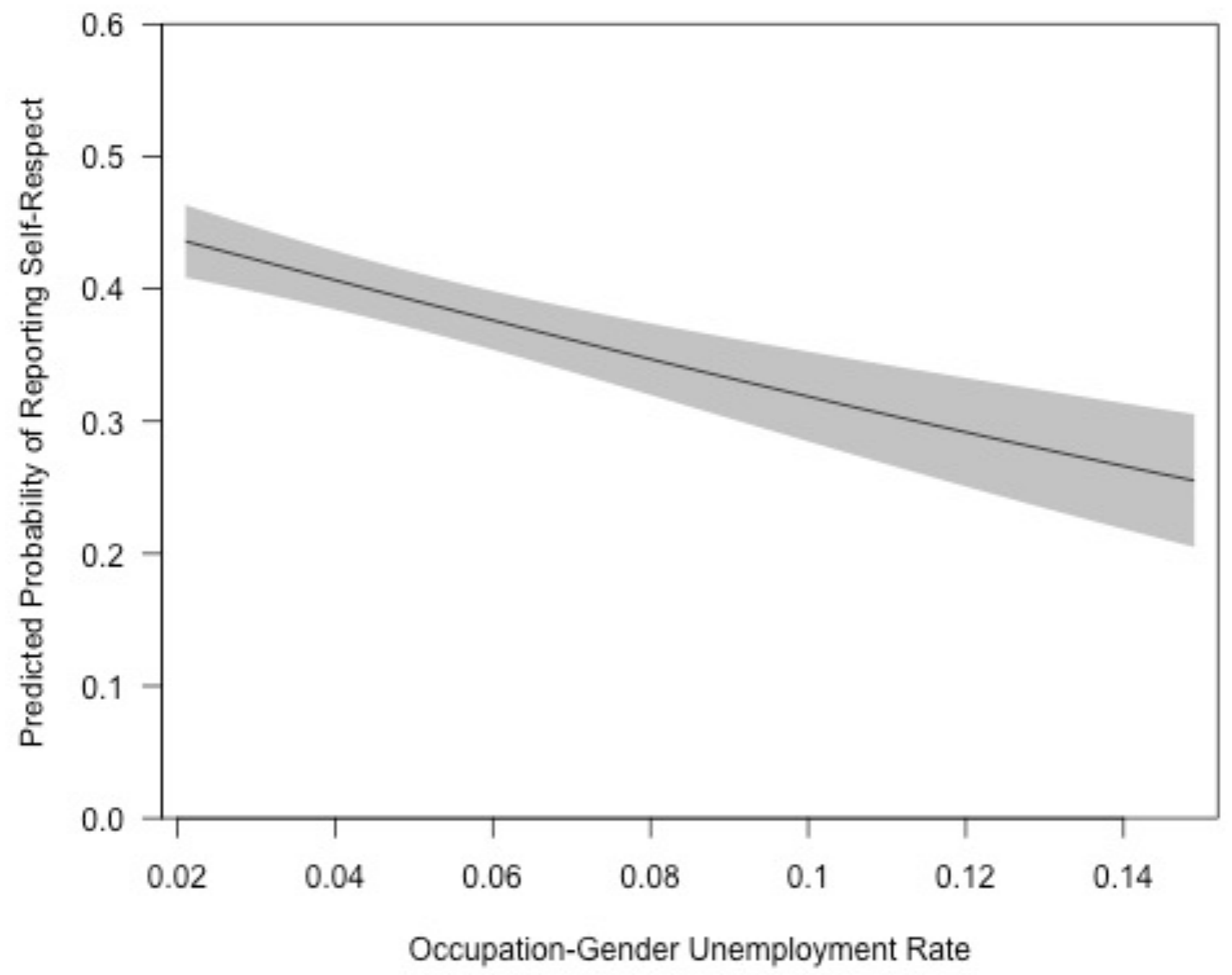

Figure 2. Expected probabilities of a typical respondent reporting having self-respect as occupation-gender specific unemployment risks increase. Shaded areas indicate $95 \%$ confidence intervals. 


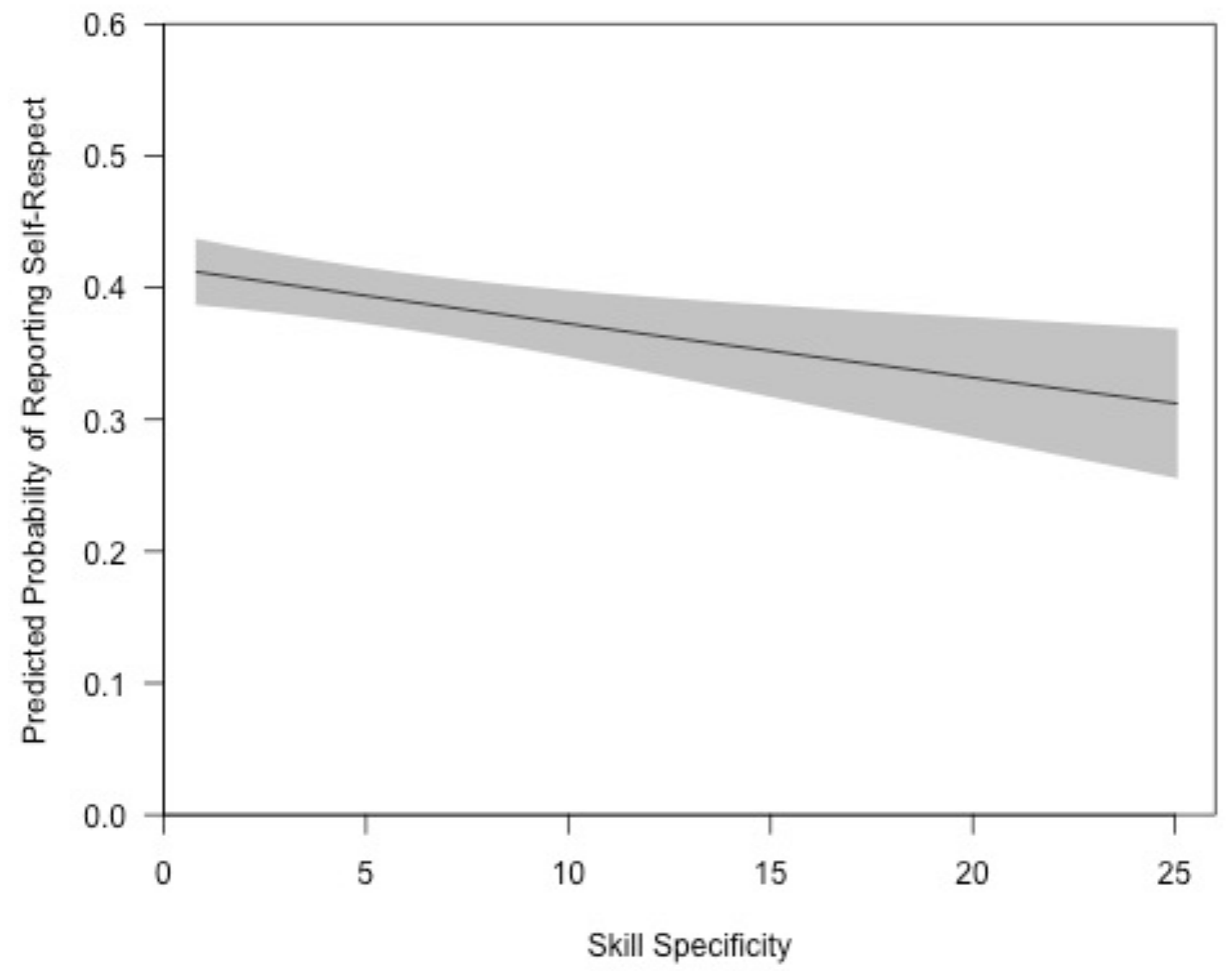

Figure 3. Expected probabilities of a typical respondent reporting having self-respect as the risk associated with specific skills increases. Shaded areas indicate $95 \%$ confidence intervals. 


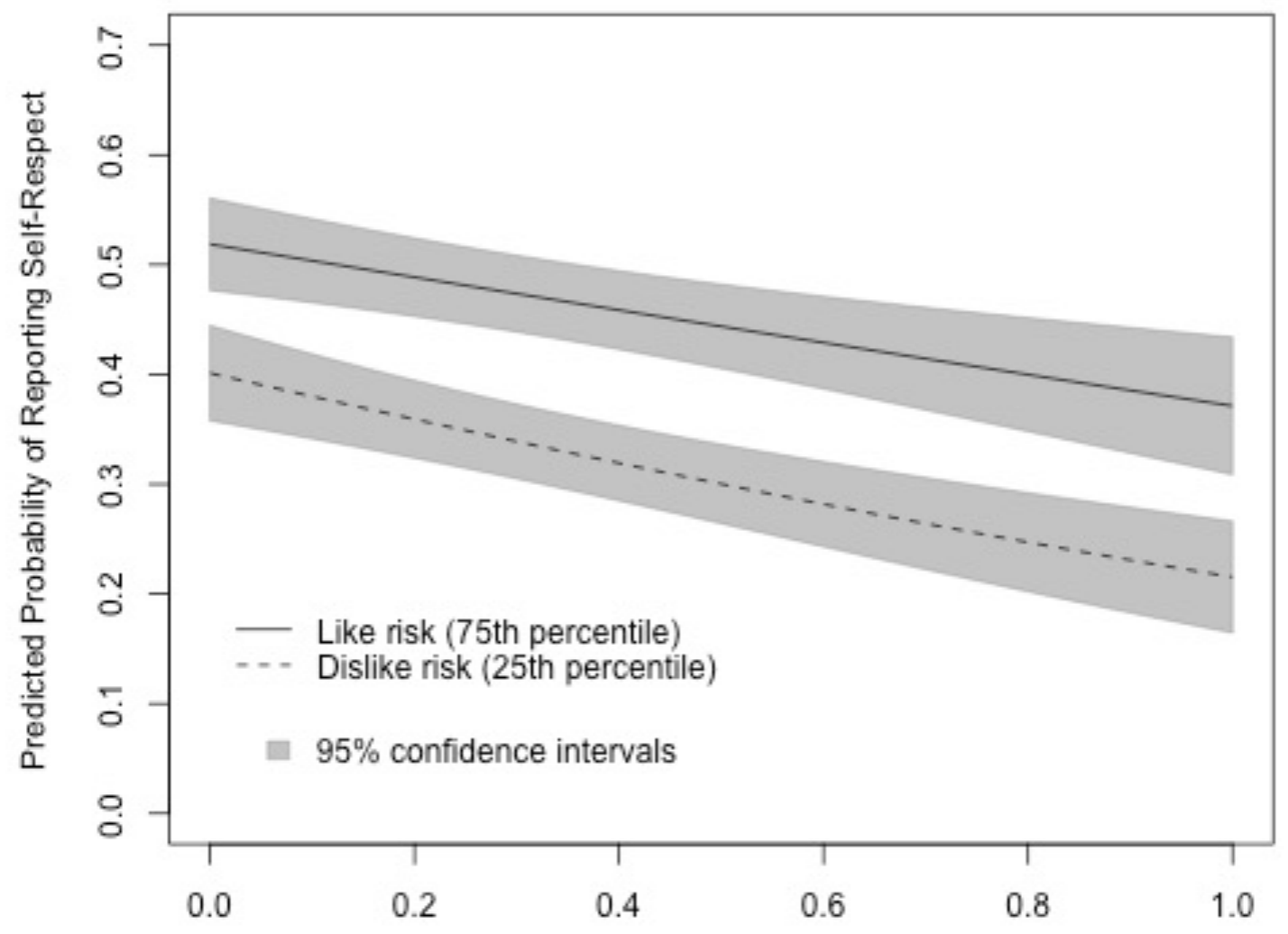

Subjective Probability of Job Loss

Figure 4: Expected probabilities of a typical respondent reporting having self-respect as subjective unemployment risk increases. The solid line shows the probabilities for those who enjoy taking risks, the dashed line those who do not. Shaded areas indicate $95 \%$ confidence intervals. 